\title{
The prediction of the evolution of grain size of land-gear forging during the die-forging process
}

\author{
Gao Lin ${ }^{1, a}$, Chen Xiaoci ${ }^{1}$, Wang Yueqiao ${ }^{1}$, Li Pengchuan $^{1}$, and Quanlin Jin $^{2}$ \\ ${ }^{1}$ China National Erzhong Group Co., 618013 Deyang Sichuan, PR China \\ ${ }^{2}$ Advanced Manufacture Technology Center, China Academy of Machinery Science \& Technologyt, \\ 100083 Beijing C, PR China
}

\begin{abstract}
The land-gear forgings are the most important structure parts, made of high strength steel $300 \mathrm{M}$. Because of the bad service environment, the microstructure and performance of the part are very strict requirements. In this article the evolution of grain size during the die-forging process is predicted, the volume fraction of dynamic recrystallization, grain refinement and development of grain size in-homogeneity, and the affection of billet shape on the grain size distribution are analyzed. The simulated results show that the grain size differences on the different billet positions are very large at the deformation beginning. But in final forging stage, the difference of the average grain size is smaller. At some center zones of the part the maximum difference of grain size is bigger than $100 \mu \mathrm{m}$.
\end{abstract}

\section{Introduction}

The land-gear forgings are the most important structure parts, made of high strength steel 300M. Because of the bad service environment, the requirements of micro-structure and performance are very high. The evolution of grain size during the die-forging process is predicted, and the differences of evolution of grain size between different areas of the billet are discussed through the computer simulation.

It is main differences between the article and other researches [4-6] that the constitutive relation [1-3] used for this article considers the dynamic recrystallization process, the dynamic/static grain growth process and mutual conversion between them.

In the numerical simulated results, the geometrical model [1] (Fig. 1), by Jin Quanlin, is used for description of dynamic recrystallization process. Different colors are used for distinguishing the recrystallized zone and unrecrystallized zone in the material micro-element. The variables used in this article are the volume fraction of dynamic recrystallization $\mathrm{X}$, average grain size $\mathrm{D}$, recrystallizaed grain size D2, unrecrystallized grain size D1, maximum difference of grain size Dc. the definition of the variables refers to reference [1].

\footnotetext{
${ }^{\text {a }}$ Corresponding author: glsichuan@163.com
}

This is an Open Access article distributed under the terms of the Creative Commons Attribution License 4.0, which permits unrestricted use, distribution, and reproduction in any medium, provided the original work is properly cited. 


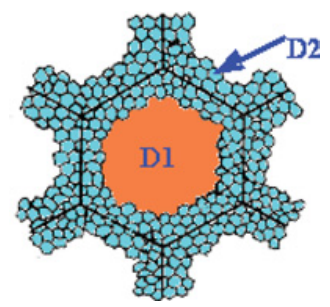

Figure 1. Geometric model of dynamic recrystallization.

\section{The constitutive telation and material parameter of $300 \mathrm{~m}$ used for the numerical simulation}

By using the conventional assumption, such as volume incompressible, isotropic, normal flow rule, the rigid visco-plastic constitutive relation can be expressed as below [1]:

$$
\left\{\begin{array}{l}
\sigma_{e}=f\left(\varepsilon_{e}, \dot{\varepsilon}_{e}, T, \chi_{\alpha}\right), \alpha=1,2,3 \ldots . \\
\dot{\varepsilon}_{i j}=\frac{3}{2} \dot{\varepsilon}_{e} \sigma_{e} s_{i j} \\
\dot{\chi}_{\alpha}=g\left(\varepsilon_{e}, \dot{\varepsilon}_{e}, T, \chi_{\alpha}\right), \alpha=1,2,3 \ldots \ldots
\end{array}\right.
$$

Where $\sigma_{e}$ is equivalent stress; $\varepsilon_{e}$ is equivalent strain; $\dot{\varepsilon}_{e}$ is equivalent strain rate; $T$ is temperature; As the internal state variable of invertible thermodynamics, $\chi_{\alpha}(\alpha=1,2,3 \ldots)$ is a scalar or tensor, and used for describing the material microstructures.

Equation (1) shows that equivalent stress is the function of equivalent strain, equivalent strain rate, temperature, microstructures variable. It is so difficult to get the general expression of the function for $300 \mathrm{M}$ that the function $\sigma_{e}=f\left(\varepsilon_{e}, \dot{\varepsilon}_{e}, T, \chi_{\alpha}\right)$ has to be replaced by a group of true stress-true strain curves, which are from hot compression tests of the cylinder specimens. Obviously, the effect of the microstructure and its evolution on the macroscopic deformation is included in these test data. The equivalent stress in the body at a point and a time can be obtained by interpolation of experimental data. The true strain vs. true strain curves here is from the reference [2]. Equation (2) is evolution equation of the plastic deformation. Equation (3) is evolution equation of the micro-structure.

By appropriately simplifying the thermal visco-plastic constitutive equation included dynamic recrystallization in reference [1], the evolution equation of the internal variables (2) can be obtained, where the unit of grain size is $\mathrm{mm}$. The material parameters are obtained are from reference [2] through compression test and metallographic experiment.

Dynamic recrystallization appears, if $\dot{\varepsilon}>0, D_{s}=D_{2}<D_{0}$.

$$
\left\{\begin{array}{l}
Z=\dot{\varepsilon} \exp \left(\frac{353732.0381}{8.31(T+273)}\right) \\
\varepsilon_{p}=0.0011 Z^{0.1664} \\
\varepsilon_{c}=0.8 \varepsilon_{p} \\
\varepsilon_{s}=0.0305 Z^{1091} \\
X=1-\exp \left(-1.0311\left(\frac{\varepsilon_{e}-\varepsilon_{c}}{\varepsilon_{s}-\varepsilon_{c}}\right)\right)^{1.3687} \\
D_{1}=D_{0}(1-X)^{1 / 3} \\
D_{2}=1.13 E 06\left(\log _{10} Z\right)^{-4.049} \\
\frac{D}{D_{0}}=\left[1+\int_{0}^{X}\left(\frac{D_{0}}{D_{2}}\right)^{3} d X\right]^{1 / 3} \\
\frac{D}{D}=-\frac{1}{3}\left(\frac{D}{D_{2}}\right)^{3} \dot{X} .
\end{array}\right.
$$




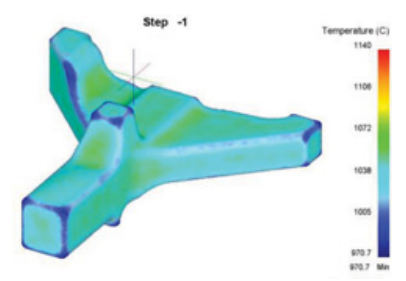

Figure 2. Initial shape and temperature contribution of the billet.

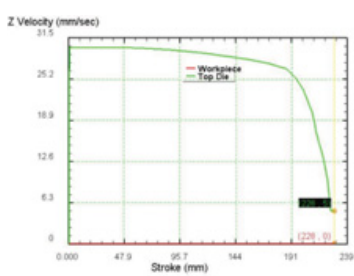

Figure 3. The depress speed of up die with its stroke.

During hot die-forging, the condition of dynamic grain growth is $\dot{\varepsilon}>0, D_{S}>D_{0}$, or $\log _{10} Z \leq 8.446$. In this case, the evolution equation of average grain size is:

$$
\left\{\begin{array}{l}
C_{1}=592210.0, C_{2}=-0.36, A=12.0 \\
D_{S}=C_{1} Z^{C_{2}} \\
B=D_{S}-D_{0} \\
D=D_{0}+B\left(1-E X P\left(-A\left(\varepsilon-\varepsilon_{0}\right)\right)\right) \\
\dot{D}=C_{2} \ln (10) D_{S}\left(1.0-E X P\left(-A\left(\varepsilon-\varepsilon_{0}\right)\right)\right) \\
\frac{d\left(\log _{10} Z\right)}{d t}+A B E X P\left(-A\left(\varepsilon-\varepsilon_{0}\right)\right) \dot{\varepsilon} .
\end{array}\right.
$$

During hot die-forging, in the cases of static grain growth $\left(\dot{\varepsilon}=0, D_{s}>D_{0}\right)$ and static recrystallization ( $\left.\dot{\varepsilon}=0, \varepsilon>0, D_{s} \geq D_{0}\right)$, the evolution equation of average grain size is:

$$
\left\{\begin{array}{l}
R_{1}=7.45 E-4, R_{2}=1.21 E-2, \\
R_{A}=7.292 E-4, \\
D_{s}=R_{1} E X P\left(R_{2} T\right), \\
R_{B}=D_{s}-D_{0}, \\
D=D_{0}+R_{B}\left(1-E X P\left(-R_{A}\left(t-t_{0}\right)\right)\right) \\
\dot{D}=R_{2} D_{S}\left(1-E X P\left(-R_{A}\left(t-t_{0}\right)\right)\right) \dot{T}+R_{B} R_{A} E X P\left(-R_{A}\left(t-t_{0}\right)\right) .
\end{array}\right.
$$

\section{Numerical simulation of the die-forging process}

The simulation software used in this article is DEFORM-3D and the developed software. The abovementioned constitutive relation is included in the developed software.

Three objects, a billet, upper die and lower die, are involved in the simulation of land gear dieforging. The billet is assumed be a rigid visco-plastic object, and is governed by the above constitutive law. The upper die and lower die are assumed be rigid. The billet shape is similar to that of the final forging by means of free forging. The billet is heated to $1140{ }^{\circ} \mathrm{C}$ in a furnace. The temperature of the billet becomes a litter lower due to the heat loss during the billet transportation. Figure 2 shows the shape and temperature distribution of the billet. The initial temperature of dies is $400{ }^{\circ} \mathrm{C}$. A hydraulic forging press is used here, upper die velocity decreases gradually with the increase of stroke, as shown in Fig. 3. 


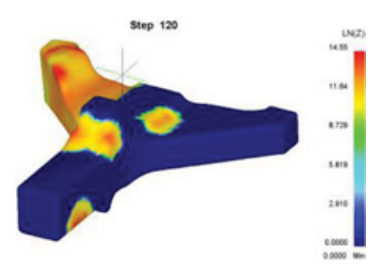

Figure 4. Distribution of Log10Z.
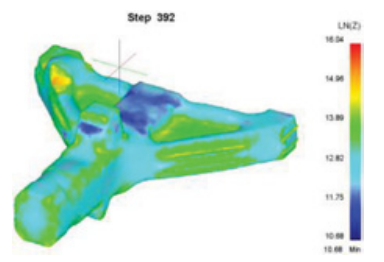

Figure 7. Distribution of $\log 10 Z$.

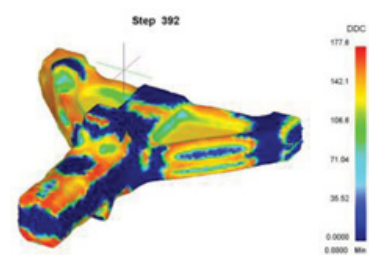

Figure 10. Distribution of Max. grain size difference.

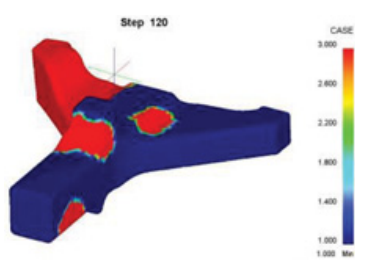

Figure 5. Distribution of Case.

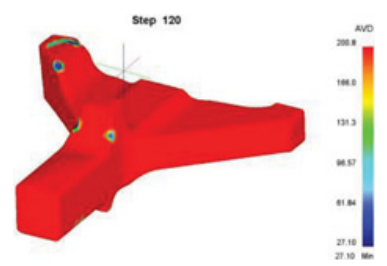

Figure 6. Distribution of average grain size.

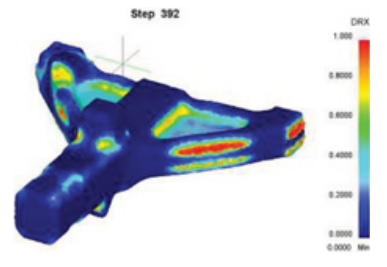

Figure 8. Distribution of dynamic recrystallization volume fraction.
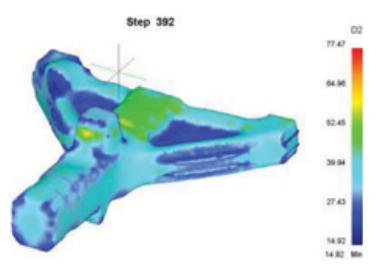

Figure 11. Distribution of recrystallized grain size.

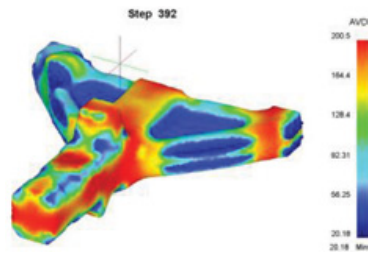

Figure 9. Distribution of average grain size.
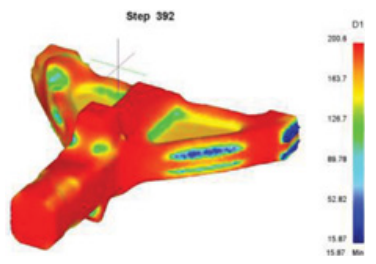

Figure 12. Distribution of unrecrystallized grain size.

\section{The simulated results and analysis}

With reference to the velocity curve in Fig. 3, the stroke of upper die is $228 \mathrm{~mm}$, the duration is 9.32 second, the simulation step is 686 . The results in step 120,392, 686 are selected to analyze the shape chages and grain size evolution of the work piece. The (stroke, time) related to the three steps are (60 mm, $2 \mathrm{~s}),(172 \mathrm{~mm}, 5.9 \mathrm{~s}),(228 \mathrm{~mm}, 9.3 \mathrm{~s})$, respectively.

\subsection{The deformation and the grain size evolution at the initial moment}

The initial moment refers to step 120, stroke $60 \mathrm{~mm}$, time is second 2. Because of the special shape, the contact area of the billet to upper die is very small so there is only local deformation in the billet and strain rate of the most regions is close to zero. Figure 4 shows distribution of the common logarithm of the parameter Z. It can be seen from Fig. 4 that deformation zones in red and yellow is smaller than the blue static zones. Zero strain rate corresponds to the zero the parameter $Z$. The critical value of $\mathrm{Z}$ between dynamic recrystallization and dynamic grain growth is $\log 10 \mathrm{Z}=8.446$. The evolution state of grain size is shown by the case distribution in the Fig. 5. The case 1 corresponds to the static grain growth, case 2 corresponds to the dynamic grain growth, case 3 corresponds to dynamic recrystallization. It can be seen that the distribution in Fig. 4 is similar to that in Fig. 5. Figure 6 is the 


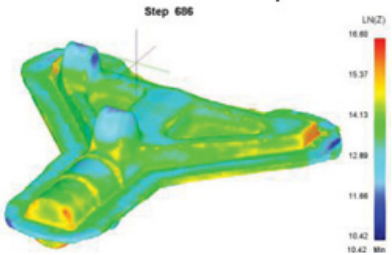

Figure 13. Distribution of $\log 10 \mathrm{Z}$.

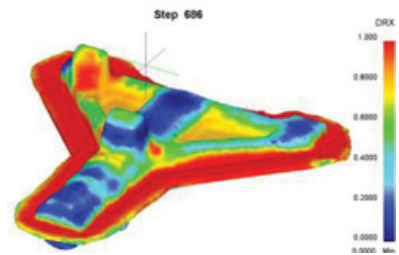

Figure 14. The volume fraction Distribution of dynamic recrystallization.

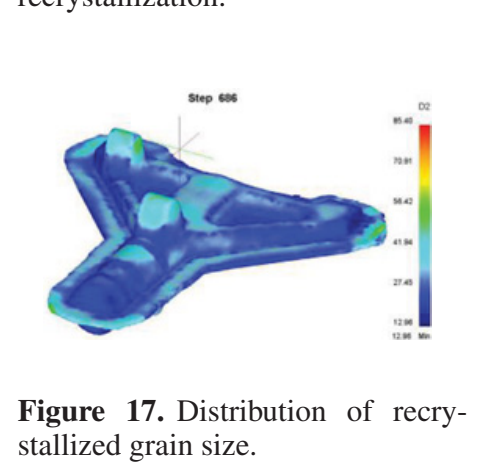

Figure 17. Distribution of recrystallized grain size.

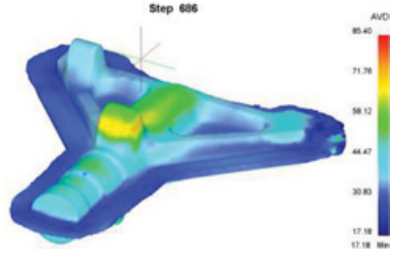

Figure 15. Distribution of average grain size.

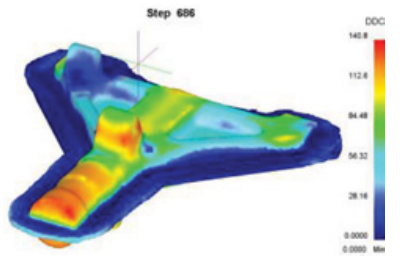

Figure 16. Distribution of Max. grain size difference.

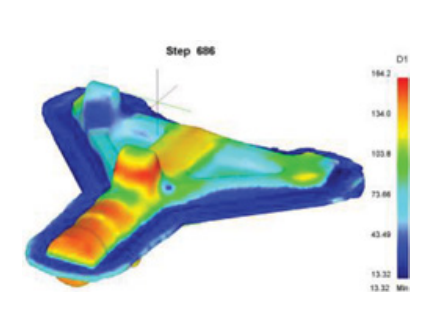

Figure 18. Distribution of unrecrystallized grain size.

distribution of average grain size, from which can be seen that the grain refinement appears in very few zones, and the slight grain growth appears in the most zones.

\subsection{The deformation and the grain size evolution at the middle moment}

The middle moment refers to step 392, stroke $172 \mathrm{~mm}$, time $5.9 \mathrm{~s}$. The large deformation and the local flash occurred. Figure 7 shows that the values of the parameter $\mathrm{Z}$ in the most zones of billet are bigger than the critical value of dynamic grain growth, $\log 10 \mathrm{Z}>8.446$, the most zones of billet are in the state of dynamic recrystallization. But Fig. 8 shows that some zones of billet didn't occur dynamic recrystallization because of the inhomogeneity of deformation.

The average grain size and the maximum difference of grain size, the recrystallized grain size, the unrecrystallized grain size are shown in the Figs. 9 and 10. The distribution of the grain size is very uniform, the minimum grain size is $20 \mu \mathrm{m}$, the maximum grain size is bigger than $200 \mu \mathrm{m}$. The maximum difference in a microscopic element is $160 \mu \mathrm{m}$.

\subsection{The deformation and the grain size evolution at the final moment}

The final moment refers to step 686 , stroke $228 \mathrm{~mm}$, time $9.3 \mathrm{~s}$. The part forging is finished, and the integral flash appears.

Figure 13 shows that the values of the parameter $\mathrm{Z}$ of the billet are all bigger than the critical value of dynamic grain growth, $\log 10 \mathrm{Z}>8.446$, the whole part are in the state of dynamic recrystallization. The Fig. 14 shows that the volume fraction of the recrystallization in some center zones of the billet is still small, because of the inhomogeneity of deformation.

The average grain size and the maximum difference of grain size, the recrystallized grain size, the unrecrystallizaed grain size are shown in the Figs. 15-18. 


\section{MATEC Web of Conferences}

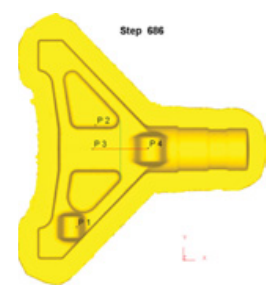

Figure 19. Position of four tracked points.

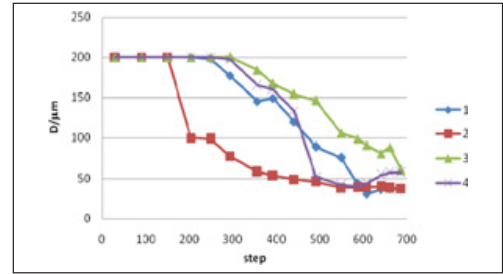

Figure 21. Variation of average grain size of four tracked points with time steps.

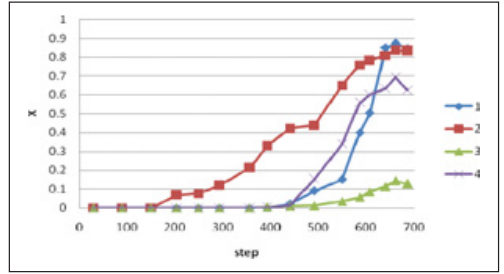

Figure 20. Variation of dynamic recrystallization volume fraction of four tracked points with time steps.

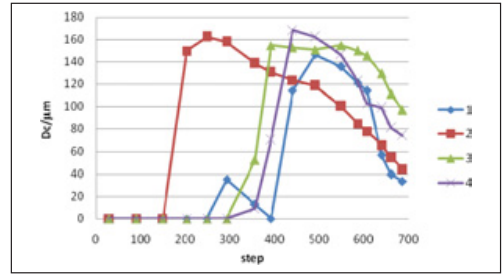

Figure 22. Variation of max grain size difference of four tracked points with time steps.

The grain size in the final moment becomes finer and more homogeneity than the middle moment. The minimum average grain size is $20 \mu \mathrm{m}$, the maximum average grain size is smaller than $80 \mu \mathrm{m}$. The average grain rate in most zones is between $30 \mu \mathrm{m}$ and $40 \mu \mathrm{m}$.

It can be seen form Fig. 16 that the maximum grain size difference in the microscopic element has been smaller than $60 \mu \mathrm{m}$.

\subsection{The grain size evolution on different points}

Due to the complex shape, the deformation process of every point of the billet is different with others, the same as the process of the dynamic recrystallization and the evolution of grain size.

Four typical points are chosen to be tracked to research the dynamic recrystallization and the evolution of grain size. Figure 19 shows the positions of four points. Figures 20-22 show the curves of the volume fraction of the recrystallization $\mathrm{X}$, the average of grain size $\mathrm{D}$, the maximum difference of grain size Dc for the chosen four points.

It is noted that the sequence of starting dynamic recrystallization on the four points is $2,4,1,3$, this is also the sequence of grain refinement, is also the sequence of transition from the uniform grain size to the non uniform state. The sequence is due to the difference in the time of starting deformation and the amounts of deformation.

At the final moment, the volume fractions of the recrystallization of the chosen four points are different with each other, the minimum value is only 0.1 on point 3 , the maximum value is close to 0.9 , on point 1 and 2 . But the average grain size on the four points is about $50 \mu \mathrm{m}$.

The variation of the maximum differences of grain size with time step on the four points is shown in Fig. 22. The maximum difference of the grain size on point 3 nearly reaches to $100 \mu \mathrm{m}$, the maximum differences of the grain size on points 1 and 2 are in $30-40 \mu \mathrm{m}$. 


\section{ICNFT 2015}

\section{Conclusion}

A numerical prediction of grain evolution during the die forging of the aircraft landing gear is carried out in this paper. The development of dynamic recrystallization, grain refinement and grain inhomogeneity are analyzed. The influence of billet shape on the grain size distribution is also discussed. It is concluded that:

For the billet, the time of starting deformation on different positions of the billet is different. This makes the difference in dynamic recrystallization and grain refinement on different positions is very large. However, at the final moment. The difference of grain evolution decreases, such as, the difference of the average grain size is between $20-60 \mathrm{~m}$, which is better result.

For the four tracked points, the three sets of curves, dynamic recrystallization volume fraction, average grain size and maximum grain size difference, have similar characteristics. It is suggested that optimizing the shape at the point 3 of the billet for reducing the difference in the deformation and the grain evolution.

\section{References}

[1] Jin Q.L. Journal of Plasticity Engineering, 1(1): 3-13 (in Chinese) (1994)

[2] Jin Q.L. Chinese Materials Science Technology \& Equipment, 7(5). (in Chinese) (2011)

[3] Qu J. Xu B. Some Improvements in Visco-plastic Model Considering Dynamic Recrystallization, Acta Mechanica Sinica, 20, 5, p 499-506 (2004)

[4] Quan. L.J. Thermal Plastic Constitutive Relation and Its Application in Forging Simulation[C] J. Huetink and F.P.T. Baaijens. Simulation of Materials Processing: Theory, Methods and Applications. Netherlands: A.A.Balkema, 257-262 (1998)

[5] K. Karhausen. R. Kopp Model for Integrated Process and Microstructure Simulation in Hot Forming[J], Steel Research, 63: 247-256 (1992)

[6] J.F. Charles. A.M. Habraken. J. Lecomte. Modeling of elasto-visco-plastic behavior of steel at high temperature[C]//J. Huetink and F. P. T. Baaijens. Simulation of Materials Processing: Theory, Methods and Applications. Netherlands: A.A. Balkema, 277-282 (1998) 